\title{
Nicaragua: Se Consolida el Estado POR Derecho (Y SE DEBILITA El EsTAdo DE DERECHO)
}

\author{
Nicaragua: The Consolidation of the Rule by Law and the \\ Weakening of the Rule of Law
}

\author{
ANDRÉS PÉREZ-BALTODANO \\ Universidad de Western Ontario, Canadá
}

\begin{abstract}
RESUMEN
En el año 2009 se acentuaron en Nicaragua tres tendencias que han marcado la gestión gubernamental del Presidente Daniel Ortega, desde que su partido -el Frente Sandinista de Liberación Nacional (FSLN)- regresara al poder en enero del 2007: la erosión de la frágil institucionalidad democrática que se estableció después del colapso del experimento revolucionario sandinista de la década de los 80; la fragmentación y polarización de la sociedad nicaragüense; y la creciente dependencia económica y política del gobierno de Nicaragua con relación al gobierno de Hugo Chávez y al proyecto de integración regional conocido como la Alternativa Bolivariana para las Américas (ALBA). Estas tres tendencias tienen una misma raíz: el supuesto -repetidamente declarado por Ortega y sus seguidores- de que el triunfo electoral del FSLN en noviembre del 2006 representó el inicio de la segunda fase de la Revolución Sandinista que triunfó en 1979 y se derrumbó con la derrota del FSLN en las elecciones de 1990.
\end{abstract}

Palabras clave: Nicaragua, sandinismo, FSLN, Daniel Ortega, partidos de oposición.

\begin{abstract}
In 2009, Nicaragua experienced the intensification of three tendencies that have defined the country's politics since the Frente Sandinista de Liberación Nacional (FSLN), led by Daniel Ortega, returned to power in January of 2007. These tendencies are: the erosion of the fragile democracy that emerged after the collapse of the revolutionary experiment conducted by the FSLN in the 1980s; the fragmentation and polarization of Nicaraguan society; and, the country's increasing economic and political dependency on the government of Hugo Chavez and the regional integration project known as Alternativa Bolivariana para las Américas (ALBA). These three tendencies share a common root: Daniel Ortega's assumption that the electoral victory of the FSLN in November of 2006 represents the beginning a second phase of the Sandinista Revolution that captured power in 1979 and that came to an end with the electoral defeat of the FSLN in 1990.
\end{abstract}

Key words: Nicaragua, Sandinismo, FSLN, Daniel Ortega, opposition parties. 


\section{INTRODUCCIÓN}

En el año 2009 se consolidó en Nicaragua lo que Luz E. Nagle llama "el Estado por derecho", un modelo de Estado en el que, contrario a lo que sucede en el Estado de derecho, la ley es instrumentalizada por el gobierno para afianzarse en el poder. ${ }^{1}$ Más concretamente, en el año 2009 se acentuaron en Nicaragua tres tendencias que han marcado la gestión gubernamental del Presidente Daniel Ortega, desde que el Frente Sandinista de Liberación Nacional (FSLN) regresara al poder en enero del 2007: la erosión de la frágil institucionalidad democrática que se estableció después del colapso del experimento revolucionario sandinista de la década de los 80; la fragmentación y polarización de la sociedad nicaragüense; y la creciente dependencia económica y política del gobierno de Nicaragua con relación al gobierno de Hugo Chávez y al proyecto de integración regional conocido como la Alternativa Bolivariana para las Américas (ALBA).

Estas tres tendencias tienen una misma raíz: el supuesto -repetidamente declarado por Ortega y sus seguidores- de que el triunfo electoral del FSLN en noviembre del 2006 representó el inicio de la segunda fase de la Revolución Sandinista que triunfó en 1979 y se derrumbó con la derrota del FSLN en las elecciones de 1990. Desde esta perspectiva, Ortega se percibe a sí mismo como el líder de un proyecto que tiene como meta una transformación radical de las estructuras sociales, políticas y económicas del país. En estas condiciones, la idea-consigna de "la revolución como fuente de derecho", utilizada por el FSLN para justificar el desmantelamiento de las estructuras de poder heredadas del somocismo en 1979, informa la lógica operativa del actual gobierno.

\section{TEMAS SALIENTES EN LA REALIDAD NACIONAL}

\section{La coyuntura política: la sombra del fraude}

La dinámica política nicaragüense en el año 2009 estuvo dominada por las consecuencias de las elecciones municipales celebradas en el país en noviembre de 2008 y, más concretamente, por las acusaciones de fraude lanzadas por diversos grupos y organizaciones contra el gobierno de Ortega. El temor al fraude había sido expresado por algunos líderes de la oposición desde antes de las elecciones y, sobre todo, a raíz de la decisión del Consejo Supremo Electoral de no autorizar la participación de la Organización de Estados Americanos (OEA), ni la del Centro Carter, como observadores de estos comicios.

El 23 de febrero, el Grupo Cívico Ética y Transparencia presentó un informe en el que señalaba que en estas elecciones "existieron condiciones de fraude sistemático y violaciones de extrema gravedad en materia de transparencia y violación de las garantías de confiabilidad de los conteos en casi todos los municipios del país y que este sesgo favoreció por diseño al partido de gobierno, tergiversando la voluntad popular en aproximadamente 40 municipios". Y agrega: "Esta aseveración no incluye otros elementos previos a los comicios, 
que favorecieron de forma sistemática al partido de gobierno, como fueron el abuso ilegal de bienes del Estado y el manejo de la inscripción y registro de votantes (cedulación), por sólo mencionar dos factores, de claro sesgo pero de difícil medición en sus efectos" ${ }^{2}{ }^{2}$

En abril, un informe de la Cooperación Técnica de Alemania (GTZ) señaló que el FSLN sólo ganó 69 alcaldías y que "al menos 37 municipios presentan grandes debilidades respecto de su legitimidad." Estas alcaldías "de endeble consenso", agrega, "están adjudicadas al FSLN". ${ }^{3}$

Por su parte, el Instituto para el Desarrollo y la Democracia (IPADE) publicó en el mes de julio otro informe en el que se señala que las elecciones efectuadas en 46 de los 146 municipios sometidos a votación fueron fraudulentas. Las irregularidades reportadas por el IPADE van "desde la impugnación masiva de Juntas Receptoras de Votos (JRV), la alteración de actas en los Consejos Electorales Municipales (CEM) y departamentales (CED), la anulación masiva de votos, entre otras". ${ }^{4}$

Las evidencias de fraude mostradas por estos y otros estudios tuvieron un impacto directo en las relaciones entre el gobierno de Ortega y la cooperación internacional. El Grupo de Apoyo Presupuestario (GAP), formado por los estados de Alemania, Finlandia, Noruega, Países Bajos, Reino Unido, Suecia y Suiza, además de organismos multilaterales como el Banco Mundial y el Banco Interamericano de Desarrollo, congeló el apoyo programado para fortalecer el presupuesto estatal nicaragüense durante los años 2008 y 2009.

En el 2008 el GAP tenía programado aportar un monto de cooperación de 121.7 millones de dólares, de los cuales solamente se desembolsaron 21 millones. Para el año 2009 se programaba un desembolso de 109.1 millones de dólares, equivalentes a donaciones de 69.1 millones y préstamos de 40 millones. $^{5}$

Por su parte, Estados Unidos a través de la Cuenta del Milenio suspendió la continuación de los desembolsos de un programa de combate contra la pobreza calculado en 175 millones de dólares. Este programa tenía una duración programada de cinco años y había estado operando por dos años y medio. El total de los fondos no desembolsados por este proyecto, como consecuencia de las desprestigiadas elecciones municipales del 2008 , ascienden a 65 millones. ${ }^{6}$

Algunos países europeos también revisaron sus programas de cooperación con Nicaragua. La cooperación danesa, por ejemplo, fue reducida en el 2009 -y finalmente cancelada en el 2010- por la "preocupante" evolución política del país.

2 Grupo Cívico Ética y Transparencia, “Informe Final Elecciones Municipales 2008”, reproducido en Envío, $\mathrm{N}^{\mathrm{o}}$ 324, 2009, http://www.envio.org.ni

3 Citado en El Nuevo Diario, "El día que se perdió el pudor", 9/11/2009. http:/ /www.elnuevodiario.com.ni

4 Confidencial, "IPADE: Hubo fraude electoral”, No 643, 26 julio-1 agosto, 2009, http:/ /www.confidencial. com.ni.

5 Centro Latinoamericano para las Relaciones con Europa (CELARE), “UE ratifica la suspensión para el 2009 del apoyo presupuestario a Nicaragua". 4/03/2009, http:/ /www.celare.org

6 Eco Diario, “EE.UU. mantiene suspensión del programa Cuenta Reto del Milenio para Nicaragua”, 11/03/2009, http://ecodiario.eleconomista.es 


\section{La coyuntura social: la lucha por "el control de las calles"}

La "preocupante" evolución política de Nicaragua en el 2009 intensificó la polarización social que ha sufrido el país desde la llegada al poder de Daniel Ortega en el 2007. Esta polarización tuvo una de sus principales expresiones en las marchas y contramarchas convocadas por el gobierno y por organizaciones de la sociedad civil que se oponen a Ortega y su proyecto neorrevolucionario.

El 28 de febrero, un grupo de estas organizaciones, agrupadas en la Unión Ciudadana por la Democracia, organizó marchas de protesta contra el gobierno en varias ciudades del país. Algunas de estas marchas fueron violentamente agredidas por grupos afines al gobierno de Ortega. Estos enfrentamientos fueron facilitados por la decisión del propio presidente de convocar marchas paralelas en las mismas ciudades en las que marchó la oposición.

La lógica que orientó la violencia desatada por los partidarios de Ortega se expresó claramente en la consigna "las calles son del pueblo y el pueblo tiene derecho a defenderlas". Esta idea contribuyó a que en el 2009 se consolidara la sensación de que la polarización política que sufre Nicaragua tiene raíces sociales profundas. Así pues, la principal consigna del gobierno: “AArriba los pobres!” escrita en los ineludibles letreros de propaganda colocados por el FSLN a lo largo y ancho del territorio nacional, adquirió, en el 2009, un sentido que va más allá de lo meramente retórico. La consigna “¡Arriba los pobres!" definió la manera en que una buena parte de los sectores que apoyan al gobierno interpretan el conflicto político nicaragüense y su participación en él.

Para los partidarios de Ortega, "la defensa de las calles" no solamente tiene el propósito político de participar en la lucha por el poder normada por la democracia electoral nicaragüense. Para estos sectores, "la lucha por las calles" y la lucha electoral tienen como propósito la conquista del poder para crear un nuevo consenso social hegemonizado por los sectores sociales marginales del país. Para muchos, entonces, la consigna“¡Arriba los pobres!" es una invitación a lograr lo que el sandinismo triunfante de 1979 no fue capaz de alcanzar en la década de 1980.

De todas las marchas y contramarchas organizadas por la oposición y por el gobierno en 2009, la más grande fue la llamada Gran Marcha de las Victorias, convocada por el FSLN el 21 de noviembre, con el objetivo de demostrar su capacidad de movilización política frente a las marchas de la oposición. Poco antes del inicio de esta marcha, Rosario Murillo, la Primera Dama del país y Coordinadora del Consejo de Comunicación y Ciudadanía para el Desarrollo y Bienestar Social, hizo declaraciones para explicar que en Nicaragua competían dos modelos, el del FSLN que es "de recuperación de derechos", y el de las elites que pretenden seguir operando como "grupos selectos que se reúnen en hoteles... unos corruptos, otros menos corruptos, pero al fin y al cabo... elites que se congregan para pretender regresar a Nicaragua [su] pasado de exclusión, mientras la mayoría celebramos que cada día que pasa avanzamos en una ruta de no discriminación". ${ }^{7}$ 
La Gran Marcha de las Victorias fue organizada como respuesta a la marcha que para ese mismo 21 de noviembre había sido convocada por la Unión Ciudadana por la Democracia. A pesar de que es prácticamente imposible obtener cifras confiables con relación al número de participantes en las marchas del gobierno y la oposición, quedó claro que las marchas pro-Ortega fueron mucho más numerosas que las organizadas por sus adversarios.

Las marchas del 2009 revelaron el abismo que separa las visiones sociales y la racionalidad política del gobierno y de la oposición. Mientras que las organizadas por el FSLN estuvieron marcadas por un sentimiento de lucha social, las de la oposición se orientaron, casi exclusivamente, a promover la defensa de la institucionalidad democrática del país. "Democracia sí, dictadura no", fue la consigna que mejor expresó el sentir de las marcha de la oposición del 21 de noviembre. ${ }^{8}$

Antes de eso, la del 28 de febrero en Managua había concluido con la lectura de un comunicado de la Unión Ciudadana por la Democracia, en el que se decía que las marchas de la oposición habían sido "un gran triunfo de la democracia sobre la dictadura". 9

Así pues, los partidarios del gobierno de Ortega tienden a ignorar o minimizar el tema de la democracia, mientras que los que se oponen al gobierno utilizan un discurso que tiende a ignorar o minimizar la realidad de la pobreza, la exclusión y la marginalidad social que sufre un amplio sector de la sociedad nicaragüense. En un país mayoritariamente pobre, la incapacidad que ha demostrado la oposición para asumir como propias las aspiraciones y necesidades de los más pobres, le otorga ventajas considerables al gobierno de Ortega.

La indiferencia social de la oposición le resuelve a Ortega el problema de explicar y defender lo que para su gobierno significa construir una Nicaragua "solidaria, socialista y cristiana". El sector del pueblo que apoya al FSLN ha internalizado la idea de que ser sandinista significa, simplemente y sin mayores complicaciones, estar al lado de los pobres. El discurso pronunciado en la Gran Marcha de las Victorias del 21 de noviembre, por la presidenta de la Federación de Estudiantes de Secundaria, expresa este sentimiento. La joven dirigente señaló que ella "jamás permitiría que la oligarquía, la elite a la que no pertenecemos, nos venga a arrebatar lo que es nuestro". ${ }^{10}$

Finalmente, vale la pena destacar que la violencia desatada contra los movimientos de oposición al gobierno durante el 2009 contribuyó a la reactivación de la memoria colectiva del pueblo nicaragüense que conoce que por el camino tomado la política nicaragüense el país puede llegar a caer en una espiral de violencia, tal como lo experimentó en el pasado.

8 Ver "Multitudinaria marcha cívica resguardada", El Nuevo Diario, 21/11/09, http:/ /www.elnuevodiario. com.ni

9 El Nuevo Diario, "Provocación Sandinista no frena marcha de UCD en Managua", 28/02/09, http://www. elnuevodiario.com.ni

10 Darling Ríos, en "Marcha de las Victorias", Gobierno de Reconciliación y Unidad Nacional, 21/11/09, http://www.presidencia.gob.ni 
Esta percepción tomó fuerza en abril, cuando voceros de la Iglesia Católica Nicaragüense aseguraron que en el Norte del país operaban grupos armados que se habían organizado para luchar contra el gobierno. La versión de la Iglesia católica no se logró confirmar. El jefe del Ejército, general Omar Halleslevens, aseguró que se trataba de grupos armados de delincuentes comunes. ${ }^{11}$

\section{La coyuntura económica: la ayuda venezolana en tiempos de crisis}

Las tensiones causadas por las elecciones del 2008 y sus consecuencias en los niveles de cooperación internacional recibida por Nicaragua se combinaron con la crisis económica mundial y su impacto en la economía nicaragüense que se contrajo en un 1,5\%. Tal como lo señala un informe del Banco Central de Nicaragua, el Producto Interno Bruto para 2009 fue de 6.149,1 millones de dólares, comparado con los 6.245,5 millones de 2008. Asimismo, el ingreso per cápita anual se redujo de 1.080,7 en el 2008 a 1.054,0 dólares en el 2009, el más bajo de Centroamérica.

El mismo informe señala que más de 42.000 nicaragüenses perdieron su empleo en 2009 como consecuencia de la contracción de la economía. Así, la tasa de desempleo abierto pasó del 6,1\% a 8,2\%. Finalmente, el informe reporta una reducción del consumo privado con relación al 2008. Este descendió del 85,3\% a 83,3\%, mientras que el consumo en el gobierno cayó del 19,9\% al 19,3\% durante el mismo período. ${ }^{12}$

En estas condiciones, el gobierno hizo tres reformas al Presupuesto General de la República para ajustar el gasto público y responder -como lo ha hecho desde que llegó al poder en el 2007- a las exigencias de los organismos financieros internacionales.

Más aún, poco antes de terminar el año, el 3 de diciembre del 2009, la Asamblea Nacional aprobó la Ley de Reforma a la Ley de Equidad Fiscal, con la que el gobierno trataría de recaudar casi mil millones de córdobas en el 2010 (0,7\% del PIB), para cerrar la brecha presupuestaria provocada, entre otras cosas, por la suspensión de la cooperación internacional para el presupuesto. ${ }^{13}$ La Ley fue aprobada con 47 votos a favor, de los cuales 38 fueron del FSLN; 23 en contra; y 15 abstenciones. ${ }^{14}$

Los problemas económicos enfrentados por Nicaragua y el gobierno de Ortega en el 2009 hubiesen sido mucho más serios de no haber sido por la cooperación que el país recibió del gobierno de Venezuela. Según el Banco Central de Nicaragua, la cooperación externa recibida en Nicaragua en el año 2009 alcanzó un total de 1.094,4 millones de dólares, 12,2 por ciento menos que el año pasado. De este monto, la cooperación venezolana alcanzó

11 El Nuevo Diario, "'Oficialmente' no hay armadas en montañas", 15/04/09, http://www.elnuevodiario. com.ni

12 Ver El Nuevo Diario, "BCN: Más de 42 mil nicas perdieron su empleo en 2009", 26/04/10, http://www. elnuevodiario.com.ni

13 Confidencial, “Ortega impone paquetazo”, No 662, 6-12 diciembre 2009, http:/ / www.confidencial.com.ni

14 La Prensa, "Parlamento aprueba reforma fiscal", 3/12/09, http://www.laprensa.com.ni 
443 millones de dólares, canalizada a través de la asistencia petrolera, inversiones directas y donaciones bilaterales. ${ }^{15}$

El crucial papel jugado por la cooperación venezolana en el 2009 fue reconocido por Ortega en un discurso en el que hizo una síntesis de su gestión de gobierno durante ese año. "Gracias al ALBA", señaló Ortega, Nicaragua había logrado "sortear la crisis". ${ }^{16}$

\section{La coyuntura internacional y subregional: entre Washington y Caracas}

Durante el 2009, Nicaragua siguió profundizando su relación con el grupo de países que integran el ALBA y, especialmente, con el gobierno venezolano de Hugo Chávez. Mientras tanto, las relaciones con los Estados Unidos transcurrieron sin mayor novedad. Ortega aprovechó su participación en eventos internacionales para denunciar las "maniobras del imperio", mientras que Washington concentraba su atención en otros países y regiones del planeta.

Como se señalara anteriormente, el apoyo económico que recibió Nicaragua de Venezuela en el 2009 fue decisivo para que el gobierno de Daniel Ortega manejara los problemas causados por el impacto de la crisis económica mundial y las suspensiones de ayuda provocadas por las acusaciones de fraude en las elecciones del 2008. Este apoyo parece haber provocado una sensación de confianza en el gobierno de Ortega que llevó a muchos de sus funcionarios a emitir fuertes condenas en contra de la cooperación internacional. El lenguaje que algunos de ellos utilizaron fue, por decirlo de alguna manera, poco diplomático. En varios discursos pronunciados en el 2009, el mismo Ortega se refirió a los países donantes como "neocolonizadores", a los montos de la cooperación internacional como "minucias" y a sus representantes, como "moscas que se paran en la inmundicia". Esto último, como una alusión a la Embajadora de la Delegación de la Comisión Europea Francesca Mosca, quien presidía la Comisión de Organismos Donantes que apoyaban el Presupuesto General de la República. Estos organismos, como se señaló anteriormente, suspendieron su apoyo a raíz de las elecciones municipales de 2008. ${ }^{17}$

La participación de Nicaragua en el ALBA colocó al gobierno de Ortega en una posición sumamente delicada a raíz del golpe de Estado ejecutado por el ejército de Honduras en contra del gobierno del Presidente Manuel Zelaya el 28 de junio de 2009. Como se recordará, Zelaya fue sacado de su casa habitación y trasladado a la fuerza en un avión militar a Costa Rica. Después de sus infructuosos intentos de aterrizar en Honduras en un avión con matrícula venezolana, el 5 de julio Zelaya se instaló en Las Manos, una pequeña población nicaragüense fronteriza con Honduras, desde donde hizo sus primeros esfuerzos para recuperar el poder.

15 Canal 15, 100\% Noticias, Informe Pastrán, “La cooperación internacional que recibió Nicaragua”, 28/04/10. http://www.canal15.com.ni

16 El 19, “Gobierno Sandinista seguirá garantizando el bienestar del pueblo", 9/01/10, http://www. el19digital.com

17 El País, "Las horas bajas de Daniel Ortega", 05/03/09, http://www.elpais.com 
Como era de esperarse, la presencia de Zelaya en territorio nacional provocó reacciones encontradas en la población nicaragüense, reforzando las tendencias polarizantes que marcaron el desarrollo del país durante el 2009. Mientras Ortega y Hugo Chávez se movilizaban para facilitar el regreso de Zelaya al poder, Eduardo Montealegre -ex ministro del gobierno de Arnoldo Alemán (1996-2002) y rival de Alemán en la contienda por liderar un liberalismo unificado- viajó en julio a Tegucigalpa para brindar su apoyo a Roberto Micheletti, el presidente de facto de Honduras. Montealegre declaró que el derrocamiento de Zelaya había sido "constitucional". ${ }^{18}$ Por su parte, el Partido Liberal Constitucionalista (PLC) de Arnoldo Alemán demandó la salida de Zelaya del territorio nacional, acusándolo de usar un "lenguaje guerrerista" y de preparar agresiones armadas contra Honduras desde territorio nicaragüense. ${ }^{19}$

El tema del golpe de Estado en Honduras ocupó la atención de tres reuniones que se realizaron en Managua el 29 de junio, con la participación de los representantes de tres organismos de integración regional: la Alternativa Bolivariana de las Américas (ALBA), la Secretaría de Integración Centroamericana (SICA) y Grupo de Río, con la participación de la Organización de Estados Americanos (OEA) y de la Unión de Naciones Suramericanas (UNASUR). Los reunidos repudiaron enérgicamente el golpe de Estado en Honduras ${ }^{20}$.

\section{CAMBIOS INSTITUCIONALES: LA BÚSQUEDA DEL PODER EN TRES ACTOS}

El sistema político nicaragüense ha funcionado, desde el año 2007, dentro de los parámetros establecidos por un pacto informal entre el FSLN y el PLC. Este arreglo ha sido repetidamente calificado como ilegítimo por la mayoría de la población en los estudios de opinión realizados en el país en los últimos tres años. ${ }^{21}$ Liberales y Sandinistas se han repartido el poder en la Corte Suprema de Justicia, en el Consejo Supremo Electoral, en el Consejo Superior de la Contraloría, en la Procuraduría de Derechos Humanos y en la Superintendencia de Bancos. El pacto, además, hizo posible la aprobación de una ley que legalizó la transferencia de propiedades del Estado a miembros del FSLN en lo que el pueblo nicaragüense bautizó como "la piñata". También dejó abiertas las puertas para la introducción de una reforma constitucional que perpetuaría el poder de los dos partidos pactantes.

Ver Confidencial, "Zelaya navega entre dos estrategias", No 644, 2-8 agosto, 2009, http://www.confidencial. com.ni

19 Caracol TV.Com, “Nicaragua, ¿en medio del conflicto de Honduras?”, 30/06/09, http: / / www.caracoltv. com.

20 Telesur, "ALBA, SICA y Grupo de Río defienden democracia hondureña", 29/06/09, http://www. telesurtv.net

21 En un sondeo realizado por M y R Consultores en marzo del 2005, por ejemplo, apenas un 19,4\% de los entrevistados opinó que el pacto FSLN-PLC contribuía a la gobernabilidad democrática del país. Ver: El Diario de Hoy, “Crece rechazo a Daniel Ortega", http:/ /www.elsalvador.com 
El pacto, además, estableció un sistema de protección personal para los líderes de los dos partidos. Daniel Ortega hizo uso de esta protección cuando, amparado en su inmunidad parlamentaria y contando con el apoyo de las bancadas sandinista y liberal en la Asamblea Legislativa, evadió las consecuencias legales de las acusaciones de abuso sexual hechas en su contra por su hija adoptiva Zoilamérica Narváez. Por su parte, Arnoldo Alemán obtuvo del pacto PLC-FSLN una diputación en la Asamblea Legislativa, que le otorgó inmunidad parlamentaria. Finalmente, el pacto entre el PLC y el FSLN promovió la autonomía del Estado con relación a la sociedad y creó condiciones favorables para la corrupción administrativa, que adquirió proporciones endémicas durante el gobierno de Arnoldo Alemán.

El pacto FSLN-PLC es un arreglo dinámico que obliga a los dos partidos que controlan el poder político en Nicaragua a competir para lograr una posición dominante dentro del mismo. En el año 2009, y como parte de esta dinámica, el FSLN promovió insistentemente las condiciones para lograr una reforma constitucional que hiciera posible la participación de Daniel Ortega como candidato presidencial en las elecciones del 2011. Como era de esperarse, el PLC se opuso a este proyecto. Nadie en Nicaragua, sin embargo, podía asegurar que el PLC no terminaría aceptando las pretensiones de Ortega, a cambio de una nueva cuota de poder dentro del pacto.

En el impredecible sistema político nicaragüense, tampoco se descartó que el FSLN recurriera al control que ejerce sobre el Poder Judicial para reabrir los tres casos de corrupción que todavía pesan sobre Arnoldo Alemán y obligarlo a pactar. Ninguna de estas dos cosas sucedieron en el 2009, lo que no significa que no puedan ocurrir más adelante. El simple hecho de que los principales analistas políticos del país las consideraron posibles, da una idea de la débil legitimidad de la que gozan las normas que formalmente rigen la democracia electoral nicaragüense.

De acuerdo a estas normas, Daniel Ortega no puede participar en las elecciones del 2011. El artículo 147 de la Constitución de la República establece claramente: “No podrá ser candidato a Presidente ni Vicepresidente de la República: el que ejerciere o hubiere ejercido en propiedad la Presidencia de la República en cualquier tiempo del período en que se efectúa la elección para el período siguiente, ni el que la hubiera ejercido por dos períodos presidenciales". 22

Ortega, entonces, no podría participar como candidato y reelegirse por dos razones: porque él ha sido presidente dos veces y porque la Constitución prohíbe la reelección en dos períodos consecutivos.

Para superar este obstáculo constitucional, el FSLN hizo uso de tres estrategias a lo largo del año. En el mes de enero, Rafael Solís, miembro de la Corte Suprema de Justicia y uno de los principales colaboradores de Daniel Ortega, confirmó que el FSLN estaba dispuesto 
a proponer la transformación del sistema presidencialista que ha existido en el país desde su nacimiento en un sistema parlamentario. Esto permitiría, en las palabras de Solís, mayor estabilidad al país. Solís no descartó la elección de Ortega y de su esposa Rosario Murillo, como Presidente y Primer Ministro respectivamente: "Todos los escenarios son posibles. Si hay reformas constitucionales y el Presidente Ortega va de candidato, Rosario podría ir en la lista de candidatos a diputados y es obvio que si reúne los votos necesarios va a ser electa Primer Ministro". ${ }^{23}$

Más tarde, en agosto de ese mismo año, el mismo Solís descartó la propuesta de creación de un sistema parlamentario señalando que por "temor o ignorancia" los otros partidos políticos se habían opuesto a la propuesta. ${ }^{24}$

A partir de este momento, el FSLN encaminó sus esfuerzos a lograr una reforma constitucional que eliminaría la restricción a la reelección de Daniel Ortega. Para iniciar la reforma constitucional, sin embargo, el FSLN necesitaba 56 votos en la Asamblea Nacional. El FSLN solamente contaba con 38. El resto estaban repartidos así: 6 de la Alianza Liberal Nicaragüense (ALN) que lideraba Eduardo Montealegre; 25 votos que controlaba el PLC de Arnoldo Alemán; y 5 votos "independientes" que, como señala la revista Envío, habían demostrado en el pasado ser "vulnerables a chantajes, presiones o prebendas". ${ }^{25}$

A pesar de sus esfuerzos, el FSLN no logró obtener el apoyo necesario para reformar la Constitución. Decidió, entonces, aprovechar su poder en la Corte Suprema de Justicia para que la Sala de lo Constitucional de ésta declarara "la inaplicabilidad" del Artículo 147 de la Constitución que prohíbe la reelección de Daniel Ortega. La racionalidad que se utilizó para justificar esta decisión fue que el artículo 147 era violatorio de los derechos constitucionales de Ortega. ${ }^{26}$ La resolución de la Corte Suprema de Justicia fue aprobada por seis magistrados afines al FSLN, en respuesta a un recurso de amparo presentado por allegados a Ortega el 15 de octubre ante el Consejo Supremo Electoral. ${ }^{27}$

El Consejo Supremo Electoral acató inmediatamente la resolución de la Corte Suprema de Justicia, con lo que quedó demostrado el control que ejerce el Poder Ejecutivo sobre estos dos poderes. La oposición al gobierno calificó la actuación de ambos como una "obscenidad jurídica". ${ }^{28}$

Mientras tanto, la población nicaragüense que se oponía a la reelección de Ortega era mayoritaria. Así se desprende de los resultados de una encuesta publicada en noviembre y que se sintetizan en la tabla siguiente:

23 La Gente, La Primerísima, "FSLN y PLC ya están negociando reformas constitucionales, avisa Payo Solís", 20/01/09, http://www.radiolaprimerisima.com

24 Envío, “¿Viento en popa, al garete o a punto de encallar?”, N 330, septiembre 2009. http://www.envio. org.ni

25 Envío, "Sin ningún borrón y con muchas cuentas nuevas", No 322, enero 2009, http: / / www.envio.org.ni

26 Ver sentencia $N^{\circ} 504$ de la Sala Constitucional de la Corte Suprema de Justicia de Nicaragua, 19/10/09., http://www.csj.gob.ni/

27 Nacion.com/elmundo, “Corte de Nicaragua abre camino a reelección de Daniel Ortega”, 20/10/09, http:// wvw.nacion.com

28 El Nuevo Diario, “Obscenidad jurídica”, 20/10/09, http:/ /www.elnuevodiario.com.ni 


\begin{tabular}{lc}
\hline Daniel Ortega quiere reelegirse, ¿sería bueno o malo para Nicaragua? \\
\hline Bueno & $34 \%$ \\
Malo & $57 \%$ \\
NS/NR & $6 \%$ \\
\hline \multicolumn{2}{c}{} \\
\hline Sí & $32,2 \%$ \\
No & $58,7 \%$ \\
\hline
\end{tabular}

Fuente: Cid Gallup.

De acuerdo al análisis que de estos datos hiciera Olda Acuña, directora de Cid Gallup, y responsable de la realización de la encuesta, Ortega se había consolidado en el FSLN aunque no había logrado ampliar el apoyo del que goza en el resto de la población. Por otra parte, la oposición aparecía fragmentada e incapaz de ofrecer una alternativa al país, más allá de su oposición a Ortega. ${ }^{29}$

\section{EL PODER EJECUTIVO}

De acuerdo al artículo 144 de la Constitución de Nicaragua, "el Poder Ejecutivo lo ejerce el Presidente de la República, quien es Jefe de Estado, Jefe de Gobierno y Jefe Supremo de las Fuerzas de Defensa y Seguridad de la Nación". El Presidente de la República, señala el artículo 151 de la misma Constitución, "determina el número, organización y competencia de los ministerios de Estado, entes autónomos y gubernamentales".

El sistema presidencial nicaragüense está marcado, en la práctica, por la lógica revolucionaria que alimenta la visión y la conducta política de Ortega la fuerte tradición caudillista que ha dominado el desarrollo político nicaragüense y la debilidad institucional del país, en especial la de los partidos políticos que forman la oposición.

Esta combinación de factores ha facilitado la personalización del poder del Estado que se encarna en la figura de Ortega y la consolidación de una cultura gubernamental marcada por el secretismo y un sentido de lealtad absoluto hacia el Presidente y su familia.

En el año 2009 la personalización del poder del Estado en la figura de Ortega se manifestó, sobre todo, en los esfuerzos del mandatario para perpetuarse en el poder. Estos esfuerzos no solamente afectaron negativamente el desarrollo democrático del país, sino también el desarrollo institucional del FSLN. La escritora y poetisa nicaragüense Gioconda Belli ilustraba esta faceta del sistema político nicaragüense en un comentario que hizo sobre la decisión de la Corte Suprema de Justicia de invalidar la prohibición constitucional a la reelección de Ortega: “Que algo tan fundamental como la restitución de la reelección 
presidencial se pueda lograr con una orden de Ortega a los magistrados (judiciales) significa que éste bien puede decir, como Luis XIV: 'El Estado soy yo'" ${ }^{30}$

En la decisión de la Corte Suprema de Justicia de invalidar la Constitución se mostró, además, el sentido de lealtad que forma parte de la cultura dentro de la que opera el Estado nicaragüense. Nadie, dentro del Estado ni dentro del FSLN, se atrevió a hacer un comentario que no fuera de total y absoluto apoyo a la decisión de la Corte.

En realidad, nunca nadie en la administración de Ortega se ha atrevido a emitir un juicio crítico contra cualquiera de las actuaciones o declaraciones del presidente. La lealtad que se demanda de los que ocupan cargos dentro del Estado es absoluta. La pena por cualquier acto de "indiscreción" es el despido. Y estos abundaron en el 2009. ${ }^{31}$

La excepción a esta regla fue el Vicepresidente de la República, Morales Carazo, ex líder del ejército irregular conocido como "la Contra", formado con el apoyo de Washington para luchar contra el sandinismo en los 1980. Morales Carazo juega un papel decorativo en la administración de Ortega. Se distancia a veces de las actuaciones del gobierno, sin que sus gestos de independencia tengan ningún impacto en la política nacional.

Finalmente, el secretismo que rodeó al gobierno nicaragüense se expresó en el insólito hecho de que durante todo su mandato, Ortega no ha dado una sola conferencia de prensa. No es sorprendente, entonces, que los funcionarios del gobierno consideren que la evasión que ellos hacen a los medios de prensa sea legítima. Así lo confirmó el Procurador de Derechos Humanos, Omar Cabezas, en abril: "Nosotros establecemos nuestra propia agenda. Hablamos cuando queremos para decir lo que queremos". ${ }^{32}$

La profunda desconfianza del gobierno hacia los medios de comunicación se intensificó en el 2009. Una evaluación del comportamiento del gobierno Ortega señala que en este año el gobierno marginó a los medios privados, acosó a sus críticos y lanzó campañas de desprestigio para silenciarlos. De acuerdo a esta misma evaluación, "el más flagrante ejemplo de intimidación gubernamental fue dirigido contra Carlos Fernando Chamorro, antiguo director de noticias de la revista sandinista Barricada en los años ochenta, quien actualmente dirige la revista Confidencial, es presidente del Centro de Investigaciones de la Comunicación (CINCO) y conduce los programas televisivos de noticias Esta Semana y Esta Noche". Y agrega: "Chamorro es uno de los periodistas más críticos e influyentes del país. Fue en su programa "Esta semana" en el cual Chamorro expuso un multimillonario plan extorsivo que involucraba al frente sandinista con el tráfico de influencias en el poder judicial". 33

También vale la pena destacar que, al igual que en años anteriores, el manejo de la cooperación venezolana continuó envuelta en el secretismo que forma parte del estilo presidencial de Ortega y de la cultura de gobierno que ha imperado durante su mandato. Como lo destaca

\footnotetext{
Gioconda Belli, ¿Ovejas todos?, El Nuevo Diario, 20/10/09, http://www.elnuevodiario.com.ni Ver, por ejemplo, La Prensa, "Entre la humillación y el despido", 11/06/09, http:/ /www.laprensa.com.ni Committee to Protect Journalists (CPJ), “Ataques a la prensa en el 2009: Nicaragua”, http:/ /cpj.org/es/2010/02/ ataques-a-la-prensa-en-el-2009-nicaragua.php 
El Nuevo Diario en un análisis de la cooperación venezolana en el 2009, ésta se canaliza hacia el Estado, sus programas sociales, pero también hacia "negocios particulares vinculados a la familia presidencial". ${ }^{34}$ Las autoridades del Estado que supuestamente velan por la transparencia gubernamental no quieren o no se atreven a aclarar el manejo que hace el gobierno de la cuantiosa y misteriosa cooperación venezolana.

La cooperación venezolana no está incluida en el Presupuesto Nacional y, por lo tanto, no está sometida a la supervisión y a los controles del Estado. Los recursos provenientes de esta cooperación son manejados por la empresa Alba de Nicaragua S.A. (ALBANISA), integrada por Petróleos de Venezuela (PDVSA) y Petróleos de Nicaragua (PETRONIC), una empresa estatal. ${ }^{35}$

Esta situación ha generado una confusa polémica sobre algo tan básico como el tipo de deuda que genera la cooperación que Nicaragua recibe de Venezuela. De acuerdo al ministro de Hacienda y Crédito Público de Nicaragua, Alberto Guevara, la cooperación venezolana no genera "deuda pública" porque es de "naturaleza privada" . ${ }^{36}$ El economista nicaragüense Sergio Santamaría, crítico del manejo de la cooperación venezolana, también considera que la deuda que se deriva de esta cooperación es "privada". ALBANISA, señala Santamaría, "es una sociedad comercial" y eso, agrega, "es ya un problema de los venezolanos...porque PDVSA es una empresa estatal que está haciendo inversiones en Nicaragua y en otros países. Los nicaragüenses no tenemos nada que ver porque no es una deuda externa de Nicaragua, o no debería ser una deuda externa, no ha sido sancionada por el Congreso". 37

Por su parte, el ex alcalde de Managua Dionisio Marenco, miembro del FSLN y negociador de los acuerdos de cooperación entre Venezuela y Nicaragua, asegura que ésta implica una deuda estatal. En este sentido, asegura que cualquier futuro gobierno tendrá que afrontar la deuda que genera la cuantiosa generación venezolana. ${ }^{38}$

Para agregar más confusión, el Presidente Hugo Chávez en una visita a Managua declaró, sin ambigüedades, que la cooperación venezolana "es una cooperación de gobierno a gobierno, de Estado a Estado, ésta es una cooperación entre gobiernos socialistas" ${ }^{39}$

\section{EL PODER LEGISLATIVO}

De acuerdo al artículo 132 de la Constitución, la Asamblea Nacional "está integrada por noventa Representantes con sus respectivos suplentes, elegidos por voto universal, igual

34 El Nuevo Diario, "Incapacidad, corrupción, despilfarro", 15/04,10, El http:/ / www.elnuevodiario.com.ni

35 La Gente, La Primerísima, “Gobierno informará a FMI sobre cooperación venezolana”, 26/02/08. http:/ /www. radiolaprimerisima.com

36 Alberto Guevara, citado en Informe21.com, “Miles de millones de dólares perdería Venezuela: Congreso de Nicaragua no reconoce la elevada deuda con Venezuela", 04/16/10.

37 Sergio Santamaría, "Somos un país mal gerenciado", La Prensa, 21/07/09, www.laprensa.com.ni

38 Dionisio Marenco, "Dionisio Marenco, ex alcalde de Managua: Ayuda venezolana 'es deuda pública'”, $L a$ Prensa, 18/04/10, www.laprensa.com.ni

39 Hugo Chávez, “Chávez defiende Petronegocios”, La Prensa, 15/04/2010, www.laprensa.com.ni 
directo, libre y secreto en circunscripciones regionales mediante la aplicación del sistema de representación proporcional, regulado por la Ley Electoral". La Constitución, además, en su artículo $\mathrm{N}^{\circ}$ 133, establece que "también forman parte de la Asamblea Nacional como Representantes propietarios y suplentes respectivamente, los candidatos a Presidente y Vicepresidente de la República que, habiendo participado en la elección correspondiente, no hayan sido elegidos; en este caso, deben contar en la circunscripción nacional con un número de votos igual o superior al promedio de los cocientes regionales electorales".

Al finalizar el año 2009, la distribución por partidos de los asientos de la Asamblea Nacional fue la siguiente:

\begin{tabular}{lcc}
\hline \multicolumn{1}{c}{ Partido } & Asientos & Número de mujeres \\
\hline Frente Sandinista de Liberación Nacional (FSLN) & 38 & 12 \\
Partido Liberal Constitucionalista (PLC) & 25 & 2 \\
Alianza Liberal Nicaragüense (ALN) & 22 & 2 \\
Movimiento de Renovación Sandinista (MRS) & 5 & 1 \\
\hline
\end{tabular}

Datos tomados de: Inter-parliamentary Union. ${ }^{40}$

La Asamblea Nacional aprobó un total de 42 leyes, once más que en 2008. Las principales fueron la Ley de Lenguaje y Señas Nicaragüenses, Ley Especial para el Fomento de la Construcción de Vivienda y de Acceso a la Vivienda de Interés Social, Ley Orgánica de la Contraloría General de la República, Ley Creadora del Banco de Fomento a la Producción, Ley de Fomento al Sector Lácteo, Ley de Seguridad y Soberanía Alimentaria, Ley General del Registro Público y la Ley del Presupuesto General de la República 2010. La Asamblea Nacional, además, aprobó 62 decretos 314 personalidades jurídicas y más de 400 millones de dólares en préstamos y donaciones. ${ }^{41}$

Las actuaciones más polémicas de la Asamblea Nacional fueron las relacionadas con el presupuesto estatal y la reforma fiscal. El Presupuesto General de la República para el 2009 se aprobó hasta el 1 de abril del 2010, con el mínimo requerido de 47 votos, los que incluyeron los 38 del FSLN, 5 votos provenientes de liberales y 4 votos de diputados que operaban como "independientes".

A través de todo el año, y como consecuencia del impacto de la crisis económica mundial y el recorte de la ayuda proveniente de la cooperación internacional, el presupuesto tuvo que ser reducido en tres ocasiones. Las tres reformas fueron aprobadas con 47 votos, el mínimo requerido.

40 http://www.ipu.org. Un asiento en la Asamblea Nacional estaba ocupado por Enrique Bolaños quien, por ser un ex Presidente, goza de este derecho de acuerdo a la Constitución del país. Bolaños opera como miembro "sin bancada".

41 Bolsa de Noticias, “Tema de fraude electoral tensionó agenda parlamentaria 2009", No 4659, 23/12/09, http:// www.bolsadenoticias.com.ni 
En octubre fue aprobada una reforma a la Ley de Equidad Fiscal con 47 votos a favor, 23 en contra y 15 abstenciones. Finalmente, el Presupuesto General de la República para el 2010 fue aprobado, nuevamente, con el mínimo de 47 votos requeridos.

Para tener una idea del grado de tensión y violencia discursiva que prevaleció durante las discusiones para la aprobación del presupuesto, dentro y fuera de la Asamblea, vale la pena citar las palabras del Presidente Ortega, celebrando el resultado de la votación parlamentaria. Dijo Ortega: "Hicieron el máximo esfuerzo (los que votaron en contra) junto con un medio de comunicación que todos conocemos que está el servicio del imperio, de los sectores más reaccionarios, más conservadores del imperio. Esos periódicos estaban llamando a los diputados a no aprobar la reforma fiscal ni el presupuesto, ese es el llamado que hacían... Es un periódico que se vende, porque los periódicos no se regalan, se venden pero además los periódicos les venden anuncios a la gente y los periódicos cobran por esos anuncios, es decir, hacen un tremendo negocio; pero además exigen subsidio y si se les dice que tienen que pagar impuestos como en cualquier otro país del mundo entonces dicen que se está atentando en contra de la libertad de prensa... Entonces están apostando a una política terrorista, porque esa es una política terrorista para que no se aprobara la reforma fiscal ni el presupuesto y algunos diputados y aspirantes a la presidencia y aspirantes a la alcaldía de Managua se prestaron al juego, pero gracias a Dios fueron más los diputados sensatos que votaron". ${ }^{42}$

El funcionamiento de los partidos en la Asamblea Nacional estuvo fuertemente condicionado por la dinámica del pacto dentro del que operan el FSLN y el PLC. Por ejemplo, el mínimo de votos obtenidos por el gobierno para la aprobación del presupuesto nacional y sus reformas contó con el apoyo tácito del PLC que en estos votos se abstuvo.

La dinámica operativa de los partidos, además, estuvo condicionada por su tendencia a operar coyunturalmente dentro de una perspectiva que en Nicaragua ha sido conceptuada como "pragmática-resignada". Desde esta perspectiva, lo políticamente deseable debe limitarse a lo coyunturalmente posible.

En el 2009, el pragmatismo resignado de los partidos políticos nicaragüenses se expresó en la tendencia de éstos a actuar dentro del marco de la realidad del poder establecido por el pacto FSLN-PLC; es decir, a actuar sin una visión de largo plazo para el país; y, ciertamente, sin posiciones filosófico-doctrinarias definidas. El peso de esta perspectiva llevó a Eduardo Montealegre y sus seguidores a adoptar una posición contradictoria, intermitente e impredecible en sus relaciones con el PLC. Sus ataques contra Arnoldo Alemán, el líder de este partido, por "pactista", "antidemocrático" y "corrupto", estuvieron intercalados por momentos en los que, ignorando sus propias acusaciones y denuncias, Montealegre hablaba de Alemán como un aliado indispensable en la lucha por la democracia nicaragüense.

El Movimiento de Renovación Sandinista (MRS), el principal grupo disidente del FSLN, también operó pragmática y resignadamente. En vez de intentar articular una visión 
renovada del sandinismo para intentar atraer las simpatías de algunos de los sectores del FSLN, el MRS jugó una política coyuntural que terminó convirtiéndolo en un virtual apéndice de la Bancada Democrática Nicaragüense (BDN) que preside Eduardo Montealegre. En el año 2009, el funcionamiento operativo del MRS en la Asamblea Nacional dependió del apoyo recibido de la BDN. Cuando en enero el legislador Juan Ramón Jiménez se retiró oficialmente del emerecismo, el BDN le "prestó" un diputado -Luis Callejas Callejas- para que no perdiera su condición de "bancada" en la Asamblea. Esta operación se repitió en abril, cuando el emerecismo perdió a la diputada Mónica Baltodano, quien decidió actuar como "independiente", por diferencias estratégicas con el MRS. En esta ocasión, el BDN le "prestó" el diputado Pedro Joaquín Chamorro Barrios. $^{43}$

\section{RELACIÓN ENTRE LOS PODERES DEL ESTADO}

Los Poderes Ejecutivo, Legislativo, Judicial y Electoral, de acuerdo al artículo 129 de la Constitución, "son independientes entre sí y se coordinan armónicamente, subordinados únicamente a los intereses supremos de la nación y a lo establecido en la presente Constitución". En la actual práctica política nicaragüense, sin embargo, el Poder Ejecutivo, encarnado en la figura del Presidente Ortega, tiende a subordinar los otros poderes del Estado.

Esto se hizo palpable, no solamente en la actuación del Poder Electoral durante las elecciones municipales de noviembre del 2008, sino en la capacidad que tuvo el Ejecutivo para proteger a los miembros de este poder frente a la protesta pública y a las críticas recibidas durante el 2009 por su papel en las mismas. En este mismo año, los medios de comunicación hablados y escritos del país siguieron haciendo uso de la expresión "la judicialización" de la política nicaragüense, para hacer referencia al uso que hizo Ortega del sistema judicial del país para consolidarse en el poder. El poder que tiene Ortega para activar o desactivar las acusaciones de corrupción que pesan sobre su rival y socio Arnoldo Alemán sigue siendo la expresión más patente de su poder para instrumentalizar la justicia en Nicaragua. Alemán tiene tres casos pendientes con la justicia nicaragüense, como advirtiera el Juez Suplente Primero de Distrito del Crimen, Ronaldo Morán Pozo, en mayo del 2009. ${ }^{44}$

El poder de Ortega en el Poder Judicial también funcionó como un recurso que usó el gobierno en contra de Eduardo Montealegre por su participación en la emisión y manejo de los llamados Certificados Negociables de Inversión (CENIS), otorgados por el Estado durante el gobierno de Arnoldo Alemán a los bancos que asumieron las deudas ocasionadas por las fraudulentas quiebras que sacudieron Nicaragua durante este gobierno. El 4 de diciembre, el Inspector General del Ministerio Público, Armando Juárez, solicitó, por quinta vez, la desaforación de Montealegre, quien goza de inmunidad por su condición

43 El Nuevo Diario, "Chamorro Barrios a Bancada MRS", 16/04/09, http://www.elnuevodiario.com.ni

44 El 19, "Alemán tiene tres casos pendientes en tribunales", 14/05/09, http:/ / www.el19digital.com 
de diputado en la Asamblea Nacional. La acusación contra Montealegre es por delitos comunes como el fraude, asociación ilícita para delinquir y estafa. ${ }^{45}$

Finalmente, es necesario tomar en cuenta las relaciones entre el Estado y tres instituciones que han jugado un papel crucial en la historia política nicaragüense en general y en las tres últimas décadas de esta historia en particular: la Iglesia Católica Nicaragüense, las Fuerzas Armadas y la Policía Nacional.

La relación entre el Poder Ejecutivo y las Fuerzas Armadas no ha variado significativamente desde 1990, cuando se logró establecer una relación institucional marcada por la subordinación de los militares al poder civil, dentro del marco que establece la Constitución. Desde ese año, las Fuerzas Armadas nicaragüenses se han mantenido al margen de la política. Esto no significa que, en algunos momentos de los últimos treinta años, no se haya al menos rumorado la intención de algunos gobernantes para instrumentalizarlas.

Con la llegada de Ortega al poder, la intención del gobierno de politizar a su favor el papel de las Fuerzas Armadas y la Policía Nacional es más que una simple especulación. Repetidamente, Ortega les recuerda a los uniformados su origen sandinista, lo que muchos interpretan como un llamado a que se integren a su proyecto neorrevolucionario.

En el año 2009, la relación entre las Fuerzas Armadas y el Ejecutivo se puso a prueba cuando de acuerdo a lo establecido por la ley éstas le recomendaron al Presidente el nombramiento del general Julio César Avilés como nuevo Comandante en Jefe, en sustitución del General Omar Hallesvens, quien, también de acuerdo a la ley, pasaba a retiro. Ortega terminó respetando la recomendación de los militares.

El caso de la Policía Nacional ha sido más complicado. Durante el año 2009 este cuerpo y su directora la Primera Comisionada Aminta Granera fueron fuertemente criticados por permitir las agresiones de las que fueron objeto las marchas convocadas por la oposición.

Finalmente, la relación entre el gobierno y la Iglesia Católica Nicaragüense durante el 2009 fue tensa. Vale la pena recordar que esta organización religiosa jugó un papel decisivo en la derrota electoral sandinista en 1990, así como en las derrotas del FSLN en las elecciones de 1996 y en las del 2002.

Para las elecciones del 2006, sin embargo, el FSLN había logrado cooptar a su adversario, el Cardenal Miguel Obando y Bravo, el hombre más importante dentro de la Iglesia Católica Nicaragüense y uno de los más influyentes en el país. En un giro que nadie ha sido capaz de explicar más allá de la especulación, el Cardenal Miguel Obando y Bravo funciona hoy como un aliado de Ortega.

Monseñor Leopoldo Brenes, el sucesor del Cardenal Obando y Bravo, mantuvo una posición crítica hacia el gobierno. Brenes, sin embargo, no tiene la fuerza política de su antecesor.

El gobierno de Ortega, por su parte, pareció interesado en evitar una confrontación con la Iglesia. Al mismo tiempo, se empecinó en apropiarse del capital simbólico de esta 
organización religiosa, un capital importante en un país marcado por una fuerte cultura religiosa.

En el 2008 y en el 2009, por ejemplo, el FSLN pagó a cientos de "rezadores" que se turnaron en las rotondas de la ciudad de Managua para orar por la paz y la reconciliación en Nicaragua. El FSLN, además, colocó estatuas de la Virgen María y enormes árboles de Navidad en estas rotondas.

Los rezadores dejaron gradualmente de funcionar. En mayo de 2009, treinta y tres de ellos se declararon en huelga de hambre, exigiendo la cancelación de salarios que según ellos nunca fueron pagados por sus contratantes. ${ }^{46}$

\section{LOS MUNICIPIOS}

La relación entre el gobierno central y los municipios en el 2009 estuvo condicionada por la sombra del fraude que marcó los resultados de las elecciones de 2008. La elección de gobiernos municipales sandinistas en estas elecciones tuvo un peso importante en el desarrollo político nacional si se tiene en cuenta que los gobiernos municipales controlados por el FSLN responden directamente al Poder Ejecutivo -personificado en Daniel Ortega- y al FSLN.

En un estudio publicado en octubre de 2009, Damaris Ruiz, Secretaria Ejecutiva de la Red Nicaragüense por la Democracia y el Desarrollo Local, explicó que el gobierno central mantiene "una relación de control directo sobre los gobiernos municipales que tienen alcaldes del FSLN". En estos casos, "todos los programas sociales del gobierno central -Hambre Cero, Usura Cero y otros- pasan por la alcaldía".

La situación es diferente en los municipios que controla el PLC. En estos casos, los programas sociales no son manejados a través de los gobiernos municipales sino a través de los llamados Consejos del Poder Ciudadano (CPC) y los Gabinetes de Poder Ciudadano (GPC), instancias de participación controlados directamente por la Secretaría de Comunicación y Ciudadanía dirigida por Rosario Murillo, la esposa de Daniel Ortega.

El estudio de la Red Nicaragüense por la Democracia y el Desarrollo Local ofrece algunas conclusiones que muestran la erosión que gradualmente sufre la frágil institucionalidad política del país y la fragmentación y polarización de la sociedad nicaragüense. El informe señala que más que en los gobiernos anteriores, la gestión local en el gobierno de Ortega ha estado marcada por una práctica "clientelista". Así pues, "los del FSLN van a trabajar con los suyos, los del PLC con los suyos y ambos partidos con sus miembros, sus amigos y sus familiares".

El informe resalta la polarización que produce el "clientelismo" y pronostica que la polarización política en los municipios "se agudizará cuando se acerquen las elecciones nacionales en 2011". 
Como algo positivo, señala que se aprecia una mayor participación de las mujeres y los jóvenes en el poder local. Sin embargo, asegura "sólo un 14\% de alcaldes son mujeres, mientras que son vicealcaldesas un $61 \%$ de mujeres." Señala además que los jóvenes que forman parte del poder local "son bastante tímidos y tienen una actitud pasiva, dejando opinar y hablar a la gente más adulta". ${ }^{4}$

\section{LA CALIDAD DE LA DEMOCRACIA}

La institucionalización de un sistema democrático requiere de un consenso social sobre las relaciones entre el Estado, la economía y la sociedad, que sirva de marco a la competencia política partidaria. En condiciones democráticas, ese consenso debe reflejar las obligaciones y los derechos de los diferentes sectores de la sociedad.

Sin un consenso social, los resultados electorales no necesariamente gozan de legitimidad. Peor aún, como lo señala la teoría política, la democracia electoral sin consenso social puede convertirse en un mecanismo para formalizar divisiones sociales expresadas a través de opciones partidarias.

A partir de las elecciones que pusieron fin al experimento revolucionario sandinista en 1990, Nicaragua ha vivido una democracia electoral sin consenso social que ha mantenido al país en una situación de crisis institucional permanente. Cada una de las elecciones que se han realizado durante la llamada transición democrática nicaragüense ha abierto un horizonte político impredecible.

Con el retorno del FSLN al poder, se abrió una etapa especialmente incierta y compleja, por la premisa revolucionaria que alimenta la gestión de gobierno de Daniel Ortega. El gobierno defiende la validez de esta premisa, a pesar de que el apoyo electoral que llevó a Ortega al poder fue apenas de un 38\% de la población del país.

La principal razón por la que el gobierno logró actuar en el 2009 como si fuese el producto de una revolución victoriosa, fue la debilidad de los partidos políticos de oposición y, particularmente, su incapacidad o falta de voluntad para articular un discurso que responda a la urgencia de la pobreza en la que vive un amplio sector de la sociedad nicaragüense.

Este sector, prácticamente ignorado por los gobiernos de la llamada transición democrática que se inició en 1990, ve en el FSLN una esperanza que se ha traducido en algunos programas sociales o, por lo menos, en una retórica incluyente que contrasta con el discurso frío e indiferente de los llamados gobiernos neoliberales que precedieron al de Ortega.

Es frente a estos sectores que Ortega puede proclamar la continuación de la Revolución Sandinista y defender su "socialismo, solidario y cristiano". "El Programa Hambre Cero", señaló Ortega en un discurso en el que revisó las labores de su gobierno en el 2009, “es

47 Envío, ¿Qué pasa en los municipios, qué pasa con los CPC?, N 331, octubre 2009. http://www.envio. org.ni 
un Programa de carácter socialista; el Programa Usura Cero es un Programa de carácter socialista; el Programa Casas para el Pueblo, es un Programa de carácter socialista; el Programa de Financiamiento con Intereses Justos es un Programa de carácter socialista; el Programa de Educación gratuita, es un programa de carácter socialista" (Gobierno de Reconciliación y Unidad Nacional). ${ }^{48}$

La efectividad de los programas sociales del gobierno de Ortega es debatible. Los funcionarios del gobierno actual y los medios de comunicación que apoyan al FSLN muestran una tendencia a exagerar su impacto. Los críticos del gobierno, por el contrario, tienden a subestimar su importancia o, incluso, a demonizarlos por "clientelistas" o "ineficientes".

Una de las evaluaciones más confiables del Programa Hambre Cero, el principal programa social del gobierno, fue dada a conocer en febrero del 2009 por la Embajada del Reino de los Países Bajos en Nicaragua. Fue realizada por el consultor holandés Paul Kester y publicada con el título Informe Evaluativo sobre el Programa Hambre Cero. El informe levanta más preguntas que respuestas. Esto no es sorprendente, dada la complejidad de los objetivos que este programa trata de alcanzar: "erradicar el hambre, la desnutrición crónica, la pobreza extrema y el desempleo en 75 mil familias rurales pobres, mediante el incremento cuantitativo y cualitativo de la producción y el consumo de alimentos proteicos, favoreciendo a la vez la sustitución del consumo de leña por el biogás". ${ }^{49}$

En el informe se señala que "a pesar de la mucha atención que el gobierno de Nicaragua da a la seguridad alimentaria, falta una política coherente con estrategias alineadas entre todos los actores nacionales y locales." Agrega que "reducir -y al final eliminar- la pobreza es un proceso de largo plazo que requiere de la voluntad de todos los actores políticos y económicos de la sociedad. Este éxito tiene que ver con la implementación de un sistema tributario justo y eficiente que permita aumentar las recaudaciones del Estado". Finalmente, señala que los insumos de este programa "pueden considerarse como gotas de lluvia que caen arbitrariamente sobre una superficie seca. Donde caen, algo hermoso podría florecer si ese pedacito de tierra es fértil gracias a un espíritu emprendedor. Si no, y en la tierra donde no caen las gotas, probablemente todo seguirá siendo igual" ${ }^{50}$

Lo que no menciona el informe -y lo que la oposición nicaragüense pareciera no lograr entender-, es que quien como los pobres de Nicaragua han vivido una eterna "sequía", cualquier "gota de lluvia", cualquier ayuda, por pasajera que sea, tiene el poder de generar la esperanza de la que se alimenta una buena parte del apoyo que recibe Daniel Ortega en la actualidad.

A estos pobres no les interesa saber si el programa que les ayuda a sobrevivir es clientelista o no. Tampoco les interesa conocer el origen de los recursos -el Banco Mundial o el más Victorias!", 08/01/10. http:/ / www.presidencia.gob.ni

49 Paul Kester, “Hambre Cero: ¿Desarrollo o gotas de lluvia?”, Envío, No 334, enero, 2010, http:/ /www.envio. org.ni

$50 \quad$ Ibíd. 
ALBA de Chávez- que se destinan para hacer posibles las "gotas de lluvia" a las que hace referencia el informe antes mencionado.

En este sentido, los sentimientos expresados por el miembro del FSLN William Grisby recogen, mejor que el discurso de la oposición, el drama existencial de los pobres de Nicaragua. Señala Grisby en un escrito publicado en agosto del 2009: “Yo escuché criticar el programa Hambre Cero porque era clientelista y asistencialista. ¿Asistencialismo? Qué me importa lo que sea si lo primero es que la gente coma. Tenemos que lograr que la gente coma como resultado de su propio trabajo, pero mientras tanto tenemos que darle de comer" ${ }^{51}$

Mientras los partidos políticos no logren articular un consenso que recoja con justicia las aspiraciones y necesidades de los diversos sectores sociales del país, Nicaragua continuará dividida entre una "izquierda" insensible a la democracia y una "derecha" indiferente al drama de la pobreza que sufre el país. Esta división continuará alimentando la polarización social que, en el 2009, alcanzó nuevos y peligrosos niveles.

51 William Grisby, "El gobierno ha hecho importantes reformas estructurales y el desafío lo tiene ahora la gente", Envío, No 329, agosto 2009, http:/ / www.envio.org.ni

Andrés Pérez-Baltodano es profesor de Ciencias Políticas en la Universidad de Western Ontario (Canadá) e Investigador Asociado del Instituto de Historia de Nicaragua y Centroamérica (IHNCA) de la Universidad Centroamericana (UCA) en Managua. Ha publicado extensamente sobre la historia política de Nicaragua y sobre la relación entre política y religión en América Latina. Su publicación más reciente es el libro La subversión ética de la realidad: Crisis y renovación del pensamiento crítico latinoamericano. Managua: IHNCA/UCA, 2009. 
